\title{
Improving Semi-analytical Predictions of Long-term Basement Heave in Over-consolidated Clay
}

\author{
Deryck Y.K. Chan ${ }^{1}$, S.P. Gopal Madabhushi, Ph.D. ${ }^{2}$, Yu Sheng Hsu, Ph.D., CEng ${ }^{3}$, and Ringo \\ Tan, Ph.D. ${ }^{4}$ \\ ${ }^{1}$ Water Consultancy Division, Mott MacDonald, Cambridge CB1 2JD, U.K.; formerly \\ Department of Engineering, University of Cambridge, Cambridge CB2 1PZ, U.K. Corresponding \\ author, email: dykc3@cam.ac.uk \\ ${ }^{2}$ Department of Engineering, University of Cambridge, Cambridge CB2 1PZ, U.K. \\ ${ }^{3}$ Foundations and Geotechnics, Mott MacDonald, Croydon CR0 2EE, U.K. \\ ${ }^{4}$ Foundations and Geotechnics, Mott MacDonald, Croydon CR0 2EE, U.K.
}

\begin{abstract}
A series of geotechnical centrifuge tests to investigate the long-term heave behaviour of basements in over-consolidated clay was performed, where the profiles of slab displacement and underslab pressure were measured simultaneously. The same prototypes were simulated using Plaxis 2D with the clay stratum represented by the small-strain hardening soil model. The results were compared and a good agreement was found in terms of the profiles of slab-soil contact pressures. The data showed that existing semi-analytical methods of long-term heave predictions can be improved by assuming a quadratic distribution of slab-soil contact pressure, and example calculations for the relaxation ratio method and the relative stiffness method are presented.
\end{abstract}

\section{INTRODUCTION}

The growth of cities has led to increasing demand for urban underground spaces around the world. When a basement structure is excavated, the permanent removal of soil overburden leads 
to a reduction in vertical effective stress, causing the remaining soil to swell. In cities with overconsolidated clay strata, such as Eagle Ford Clay in Texas and London Clay in England, this process of swelling continues after the completion of the basement structure, generating upward displacement and heave pressures on the base slab as the clay re-equilibrates.

This process is known as "long-term heave" and engineers are required to design the base slab to restrain or allow for these gradual movements and soil pressure changes. These changes in soil pressure and consequent heave movements often continue for over a decade beyond structural completion (Chan et al. 2018).

A range of methods of various levels of complexity are being used in the industry to predict the heave movements and under-slab swell pressures that will emerge as the clay continues to consolidate after the completion of structural construction. As a first estimate, some designers assume that $50-65 \%$ of the pre-existing effective overburden will manifest itself as an upward loading pressure at the formation level.

\section{Non-linear Analytical Methods}

The volumetric stress-strain relationship of stiff clays is highly non-linear. Therefore, semianalytical methods to predict soil-structure interaction in basement heave problems will require the use of constitutive models that account for this soil non-linearity. The simplified non-linear model (O'Brien and Sharp 2001) is often adopted, and this model forms the basis of "relaxation ratio method" (sometimes known as the "non-FE method") which is popular among designers (Chan and Madabhushi 2017; Simpson 2018). The procedure of this method is illustrated in Fig. 1 and its salient steps are described below:

1. Plot a soil curve to represent the non-linear stiffness of the clay stratum, using constitutive relationships such as Steinbrenner's solution of vertical stress distribution and an oedometric stress-strain curve (see e.g. Padfield and Sharrock 1983; Bowles 1997);

2. Set a movement limit based on serviceability requirements;

3. From the intersection between the movement limit line and the soil curve, draw a straight 


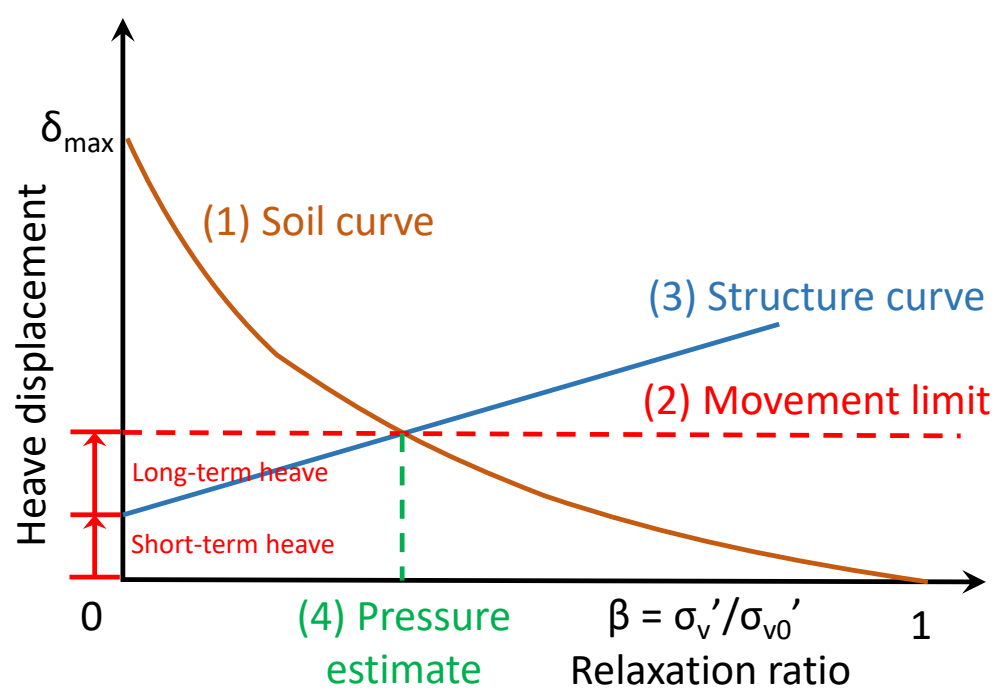

Fig. 1. Illustration of the relaxation ratio method to predict soil-structure interaction of basement slabs in stiff clay

line that represents the stiffness of the structure. From this line, extract the stiffness and design a slab with this stiffness.

4. Verify that the slab can carry the estimated heave pressure that is associated with the chosen movement limit.

Simpson 2018 demonstrated that this method is conceptually flawed because it incorrectly predicts that slab-soil contact pressures would depend on soil stiffness even when the slab is completely restrained. Nevertheless, it produces conservative estimates of heave as long as there is a net relaxation of vertical stresses.

\section{Finite Element Methods}

At the sophisticated end of the spectrum, finite element (FE) methods are used. The small-strain hardening soil model (HSS, Obrzud and Truty 2011) is a popular constitutive model to simulate soil-structure interaction phenomena in over-consolidated clay, because it is a built-in feature in recent editions of Plaxis (see Plaxis 2017). It combines several stiffness and yield characteristics that are appropriate for over-consolidated clay behaviour:

- Cap surface (Fig. 2, cf. Modified Cam Clay) to model the wet-side volumetric yield 


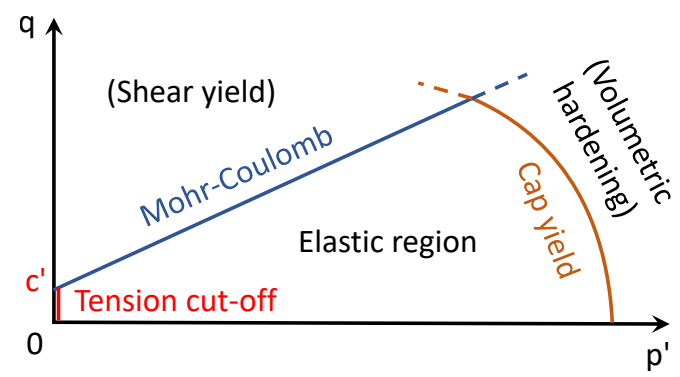

Fig. 2. Illustration of yield surfaces in HSS model

behaviour of the clay, though this is seldom triggered in a simulation of construction in over-consolidated clay beyond model initialisation;

- Mohr-Coulomb yield surface and tension cut-off to approximate the dry-side shear yield behaviour of the clay, addressing the common observation that Cam Clay-type models over-estimate dry-side yield strength (Fig. 2, cf. Hvorslev surface)

- Shear-hardening mechanism to capture the gradual change in stiffness as the soil approaches ultimate strength

- Small-strain stiffness degradation mechanism to capture the very high initial shear stiffness and subsequent rapid drop of stiffness with increasing strain (Fig. 3, cf. Viggiani and Atkinson 1995)

The constitutive parameters of HSS are formulated in terms of effective stress. It captures time dependency through excess pore pressure dissipation, but does not consider creep effects.

More advanced constitutive models are available, such as the general soil-hardening model (Nejjar et al. 2019), the Advanced Cam Clay model (Wongsaroj et al. 2007), and the A* model (Eadington and O'Brien 2011). However, these models are less prevalent than HSS because they are not standard components of commercially available geotechnical engineering software packages. Some of these models also require significantly more physical data to calibrate their constitutive parameters than HSS, so their usage is restricted to scenarios where detailed site investigation data are available and the resource commitments of a bespoke analysis are justified.

Regardless of the method of heave prediction, physical data are required to calibrate the consti- 


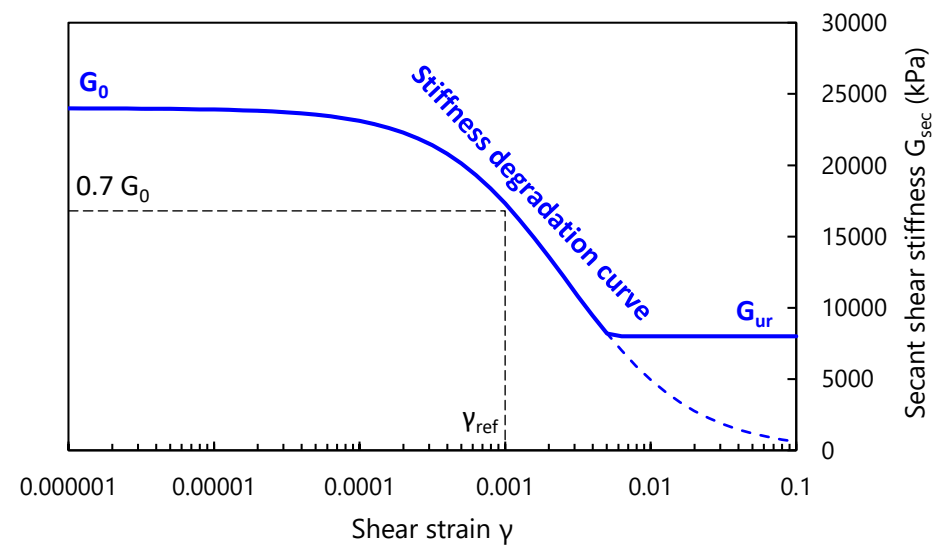

Fig. 3. Illustration of stiffness degradation in HSS model

tutive parameters. Ideally, site monitoring data of actual heave pressure and displacement should be used (Simpson 2018). There have been a few notable cases of long-term basement heave monitoring in stiff clay such as Horseferry Road Basement, Westminster (May 1975, Chan et al. 2018); Shell Centre, Waterloo (Pumphrey 2001); and the British Library, St Pancras (Simpson and Vardanega 2014). However, these instances of extensive monitoring are exceptions rather than the rule because it is difficult to carry on monitoring when a building basement is in operation.

Physical models of basement-clay interaction can be used to address this gap in available data. Geotechnical centrifuge modelling in particular is a desirable method of investigation, because centrifugal acceleration allows the time-scale and dimensions of the prototype heave problem to be scaled down. A 1:100 scale model of a basement excavation in clay, performed at 100 times Earth's gravity, can simulate four years of prototype heave behaviour in four hours of centrifuge operation (Table 1). The frequencies of loads in clay heave phenomena are very low compared to that of dynamic loads, so there is no need to scale the viscosity of the pore fluid and it is appropriate to use water as pore fluid in the centrifuge model. Laboratory testing also allows extensive use of miniature instrumentation to monitor the behaviour of the soil and the model structure, providing targeted data to aid the refinement of design methods.

This paper will compare a series of centrifuge tests on the long-term heave behaviour of rectangular basements with FE simulations of the same prototypes using the HSS constitutive 
TABLE 1. Geotechnical centrifuge scaling laws for long-term heave phenomena, after Madabhushi 2014

\begin{tabular}{lcc}
\hline \hline Parameter & Model scale & Prototype scale (prototype/model) \\
\hline Gravity $-\mathrm{g}\left(\mathrm{ms}^{-2}\right)$ & $\mathrm{N}$ & 1 \\
Length $-\mathrm{L}(\mathrm{m})$ & 1 & $\mathrm{~N}$ \\
Force $-\mathrm{F}\left(\mathrm{N}=\mathrm{kgms}^{-2}\right)$ & 1 & $\mathrm{~N}^{2}$ \\
Density $-\rho\left(\mathrm{kgm}^{-3}\right)$ & 1 & 1 \\
Stress $-\sigma\left(\mathrm{Pa}=\mathrm{Nm}^{-2}\right)$ & 1 & 1 \\
Strain $-\epsilon($ dimensionless $)$ & 1 & 1 \\
Axial stiffness of prop - EA (N) & 1 & $\mathrm{~N}^{2}$ \\
Bending stiffness of slab - EI/b $(\mathrm{Nm})$ & 1 & $\mathrm{~N}^{3}$ \\
Seepage permeability - $\mathrm{k}\left(\mathrm{ms}^{-1}\right)$ & 1 & $1 / \mathrm{N}$ \\
Coefficient of consolidation $-c_{v}\left(\mathrm{~m}^{2} \mathrm{~s}^{-1}\right)$ & 1 & 1 \\
Time - $\mathrm{t}(\mathrm{s})$ & 1 & $\mathrm{~N}^{2}$ \\
\hline \hline
\end{tabular}

model. The aim of this study is to evaluate the goodness of fit between the two methods of investigation, understand the relevant mechanisms of deformation, and propose improvements to the semi-analytical methods of long-term heave prediction.

\section{REPRESENTATIVE PROTOTYPES}

This paper presents two basement prototypes which were each modelled by both centrifuge testing and FE analyses. Each prototype involved a $16 \mathrm{~m}$ thick stratum of over-consolidated clay overlain by a $15 \mathrm{~m}$ thick layer of sand.

Each basement model was $15 \mathrm{~m}$ deep, $15 \mathrm{~m}$ wide, and buried $15 \mathrm{~m}$ into the ground, as illustrated in Figs. 4 and 5. Two different base slab stiffnesses were investigated: the stiff basement's bending stiffness matched that of a typical $1 \mathrm{~m}$ thick reinforced concrete slab; the flexible basement was designed to be flexible to generate large heave displacements to aid the identification of deformation mechanisms (Table 2).

The basement models were placed above the clay layer, with a thin drainage layer separating the base slab from the clay. The water table was maintained at the top of the drainage layer as shown in Fig. 4. This models the common construction practice of providing under-slab drainage 
TABLE 2. Specification of basement structure prototypes

\begin{tabular}{|c|c|c|}
\hline Prototype & Flexible basement & Stiff basement \\
\hline Basement footprint & $\begin{array}{c}150 \mathrm{~mm} \times 300 \mathrm{~mm} \text { (model) } \\
15 \mathrm{~m} \times 30 \mathrm{~m} \text { (prototype) }\end{array}$ & $\begin{array}{c}150 \mathrm{~mm} \times 300 \mathrm{~mm} \text { (model); } \\
15 \mathrm{~m} \times 30 \mathrm{~m} \text { (prototype) }\end{array}$ \\
\hline $\begin{array}{l}\text { Basement slab and } \\
\text { wall specification }\end{array}$ & $1.22 \mathrm{~mm}$-thick brass plate & $3.25 \mathrm{~mm}$-thick stainless steel plate \\
\hline $\begin{array}{l}\text { Self-weight of } \\
\text { basement model }\end{array}$ & $3.38 \mathrm{~kg}$ (model scale) & $5.78 \mathrm{~kg}$ (model scale) \\
\hline $\begin{array}{l}\text { Basement slab and } \\
\text { wall stiffness (EI/b) }\end{array}$ & $\begin{array}{c}14 \mathrm{Nm}^{2} / \mathrm{m} \text { (model); } \\
14 \mathrm{MNm}^{2} / \mathrm{m} \text { (prototype) } \\
\text { (Represents } 300 \text { mm-thick } \\
\text { reinforced concrete) }\end{array}$ & $\begin{array}{c}533 \mathrm{Nm}^{2} / \mathrm{m} \text { (model); } \\
533 \mathrm{MNm}^{2} / \mathrm{m} \text { (prototype) } \\
\text { (Represents } 1000 \mathrm{~mm} \text {-thick } \\
\text { reinforced concrete) }\end{array}$ \\
\hline $\begin{array}{l}\text { Light superstructure } \\
\text { weight }\end{array}$ & $\begin{array}{c}2.2 \mathrm{kN} \text { (model) } \\
22 \mathrm{MN} \text { (prototype) } \\
\text { (Represents 3-storey } \\
\text { basement structure) }\end{array}$ & $\begin{array}{c}2.2 \mathrm{kN} \text { (model) } \\
22 \mathrm{MN} \text { (prototype) } \\
\text { (Represents 3-storey } \\
\text { basement structure) }\end{array}$ \\
\hline $\begin{array}{c}\text { Heavy superstructure } \\
\text { weight }\end{array}$ & $\begin{array}{c}10 \mathrm{kN} \text { (model) } \\
100 \mathrm{MN} \text { (prototype) } \\
\text { (Represents 10-storey } \\
\text { building above ground) }\end{array}$ & $\begin{array}{c}10 \mathrm{kN} \text { (model) } \\
100 \mathrm{MN} \text { (prototype) } \\
\text { (Represents 10-storey } \\
\text { building above ground) }\end{array}$ \\
\hline
\end{tabular}

to eliminate buoyancy loads.

The field of simulation of each model was $85 \mathrm{~m}$ wide. The base of the clay layer was supported on a rigid but permeable base to simulate weathered bedrock with relatively high permeability. Fig. 4 shows the general arrangement of the prototype.

\section{CENTRIFUGE MODEL}

The centrifuge tests in this research were performed at $100 \mathrm{~g}$ (multiples of Earth's gravity), which means the prototype dimensions were scaled down by a factor of 100 to give the model dimensions. The centrifuge models were built inside a cylindrical model container of $850 \mathrm{~mm}$ diameter, giving a simulation field of $85 \mathrm{~m}$ prototype width. The basement models were $150 \mathrm{~mm} \times$ $300 \mathrm{~mm}$ in plan area, giving a prototype footprint of $15 \mathrm{~m} \times 30 \mathrm{~m}$. Two props $100 \mathrm{~mm}$ apart from each other provided excavation lateral support slightly above ground surface level (Fig. 5). As 


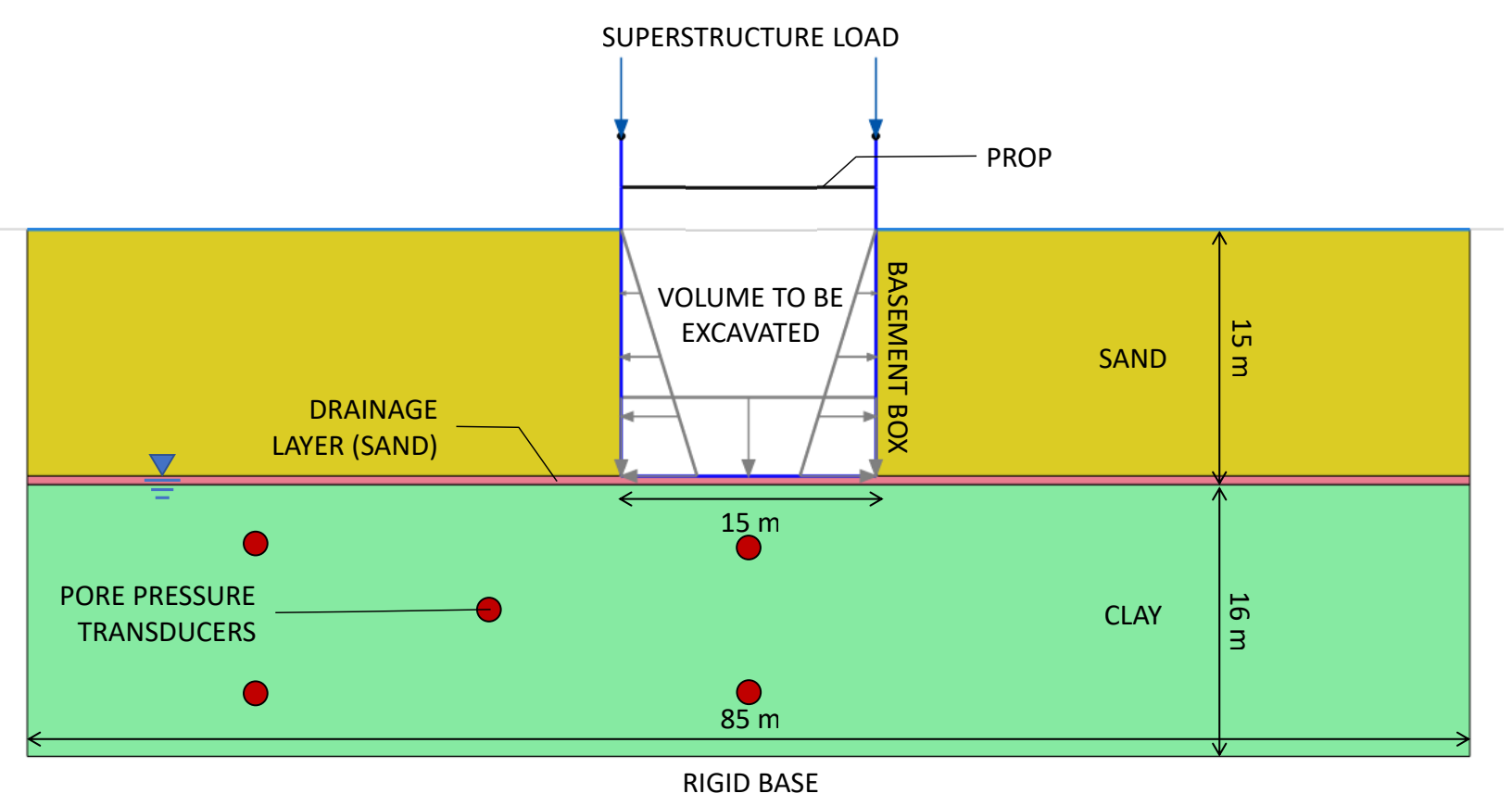

Fig. 4. Elevation drawing of representative prototype

the basement is twice as long as it is wide, the mid-section can be approximated as a plane strain problem.

In each experiment, the over-consolidated clay layer was formed as a single layer. Speswhite kaolin powder was mixed with water in a vacuum mixer to give a slurry of water content $\mathrm{w}=125 \%$, or $160 \%$ of the liquid limit. The slurry was poured into the model container and compressed in a hydraulic consolidometer to a maximum effective stress of $800 \mathrm{kPa}$ (Fig. 6). The internal wall of the model container was greased to minimise friction between the consolidating clay and the container. The piston load was then reduced gradually from $800 \mathrm{kPa}$ to $80 \mathrm{kPa}$, taking care to avoid cavitation by ensuring that the negative excess pore pressure never exceeded $100 \mathrm{kPa}$. The model container and clay were then removed from the consolidometer. This procedure of clay sample preparation has been used for over three decades by previous centrifuge modellers (see e.g. Mair et al. 1984; Ellis and Springman 2001; Lam et al. 2012).

The clay was trimmed to the target thickness of $160 \mathrm{~mm}$ to give a prototype stratum thickness of $16 \mathrm{~m}$. The basement model was installed and then dry Hostun sand was poured around the 


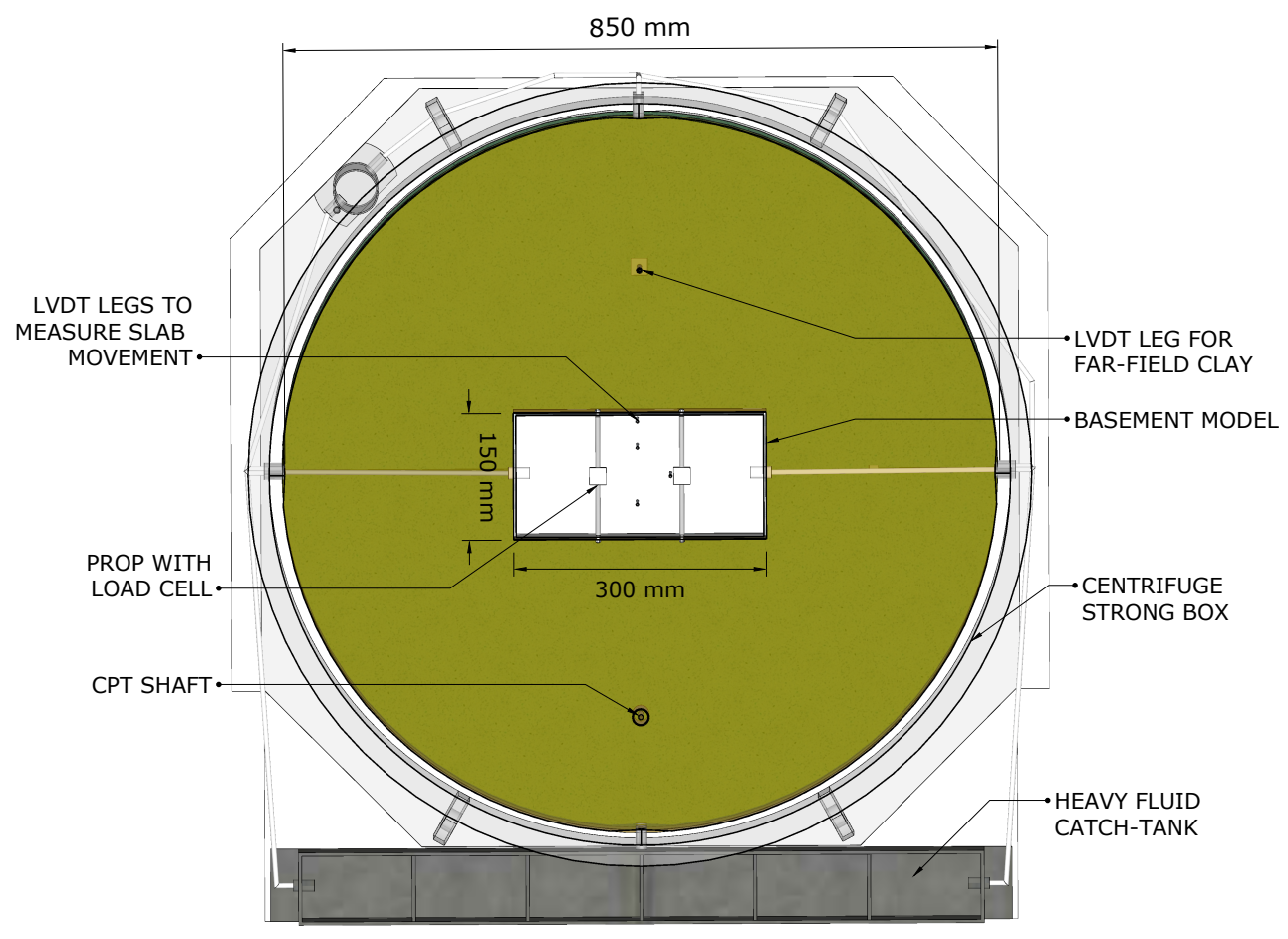

Fig. 5. Cut-out plan view of centrifuge model

basement using an automatic sand pourer (Madabhushi et al. 2006) at a density of $1625 \mathrm{~kg} / \mathrm{m}^{3}$.

In each centrifuge test, the basement cavity would be filled with a heavy fluid (sodium polytungstate solution) of the same density as the dry sand outside the basement. Excavation was simulated by removing this heavy fluid from the basement cavity during centrifuge flight and draining it to a catch-tank at a lower elevation. Subsequently, an electrical actuator would apply a vertical load onto the top of the basement walls to model the construction of a light superstructure. Towards the end of the experiment, the actuator load would be increased to simulate the short-term effect of building a heavy superstructure. Fig. 7 shows the centrifuge model inside the beam centrifuge and Table 3 provides the full experimental sequence.

In the centrifuge tests, the model base slab was already present at the time of excavation. In real-life basement construction projects, the base slab will be cast following excavation; this process 


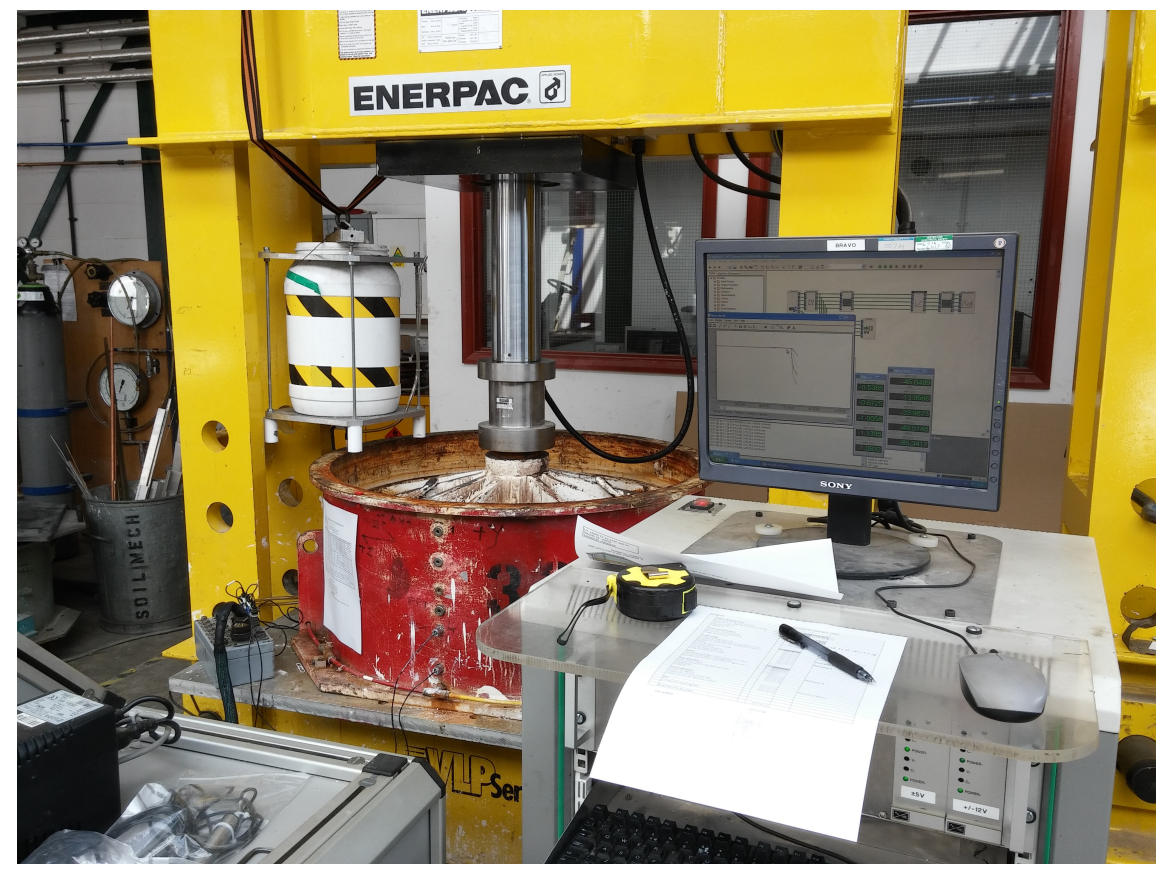

Fig. 6. Photograph of clay layer compressed and monitored in hydraulic consolidometer

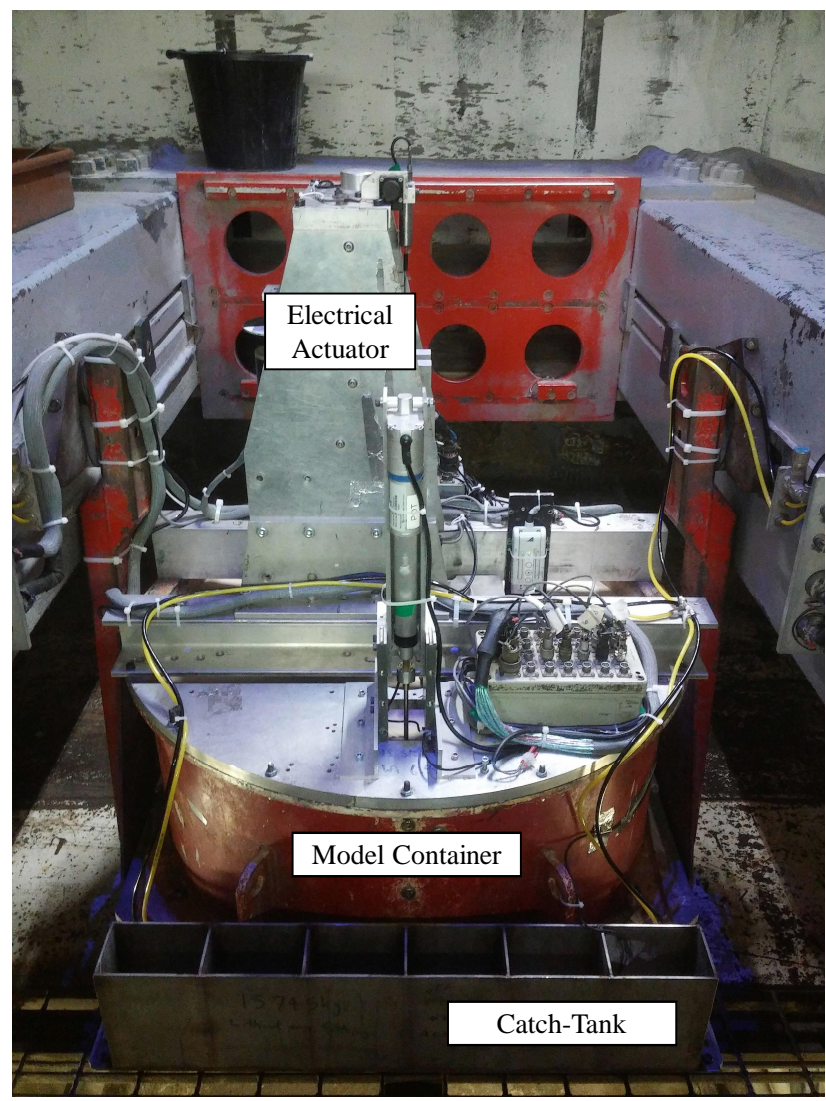

Fig. 7. Annotated photograph of centrifuge model assembled into beam centrifuge 
TABLE 3. Experimental sequence

\begin{tabular}{|c|c|c|}
\hline Number & Procedure (centrifuge) & Procedure (FE) \\
\hline 1 & Spin-up to $100 \mathrm{~g}$ (149 rpm) & $\begin{array}{l}\text { Replace the soil in the prototype basement } \\
\text { location with the basement structure and } \\
\text { line loads representing the heavy fluid }\end{array}$ \\
\hline 2 & \multicolumn{2}{|c|}{ Allow the model to consolidate to equilibrium } \\
\hline 3 & $\begin{array}{l}\text { Excavation stage: open valves to drain half of } \\
\text { the heavy fluid from the basement; then close } \\
\text { valves and for } 5 \text { weeks ( } 5 \text { minutes in model } \\
\text { scale); then drain the remaining heavy fluid. }\end{array}$ & $\begin{array}{l}\text { Excavation stage: turn off line loads } \\
\text { representing the heavy fluid over a } \\
\text { duration of } 5 \text { weeks }\end{array}$ \\
\hline 4 & \multicolumn{2}{|c|}{ Hiatus: Wait 15 weeks ( 15 minutes in centrifuge) } \\
\hline 5 & \multicolumn{2}{|c|}{$\begin{array}{l}\text { Impose loads at the top of the walls to simulate the construction of the light building } \\
\text { over a duration of } 1 \text { week ( } 1 \text { minute in centrifuge) }\end{array}$} \\
\hline 6 & \multicolumn{2}{|c|}{ Allow the clay to consolidate to equilibrium } \\
\hline 7 & \multicolumn{2}{|c|}{$\begin{array}{l}\text { Increase the loads at the top of the walls to simulate the construction of } \\
\text { the heavy building over a duration of } 1 \text { week ( } 1 \text { minute in centrifuge) }\end{array}$} \\
\hline 8 & Turn off the centrifuge & Allow the model to consolidate to equilibrium \\
\hline
\end{tabular}

has not been modelled in this investigation.

The centrifuge model provided five types of instruments:

- Linear variable differential transformers (LVDT) measured the vertical displacements of several points of the base slab and of the far-field clay surface;

- Strain gauges along the centre-line of the basement models measured the bending curvature of the slab and walls;

- Load cells measured the axial load in each prop;

- Pore pressure transducers in the clay were used to monitor the progress of each experiment and measure the pore pressure response to excavation and superstructure loading;

- Tekscan tactile sensing mats measured the distribution of slab-soil contact pressures. 


\section{Numerical Models}

The software used for the FE analyses in this research was PLAXIS 2D 2017-01 (Plaxis 2017). The over-consolidated clay was represented by a small-strain hardening (HSS) model (Obrzud and Truty 2011) to capture the non-linear stiffness of the clay. The constitutive parameters were calibrated using triaxial test data from Vardanega et al. (2012) and one-dimensional compression data from the preparation process of the clay samples used in the experiments reported in this paper. The sand was represented by a Mohr-Coulomb model with constitutive parameters obtained from the experiments reported in Heron (2013) and Deng and Haigh (2018). Table 4 summarises the constitutive parameters used in the finite element simulations. The software package and soil constitutive models were chosen to match current practices in industry where finite element models of basement heave in over-consolidated clays are needed. Chan and Madabhushi (2020) provides further details about the numerical modelling set-up.

The models were simulated in plane-strain conditions at prototype scale. The basements were modelled as linear-elastic plate elements whose bending stiffness values matched the equivalent basement models in the centrifuge tests. The props were included in the FE model and their stiffness was calculated per metre length of the wall, giving a value of $1.98 \times 10^{9} \mathrm{~N} / \mathrm{m}$. The stiffness of the end walls of the basements were not included owing to the plane strain assumption.

The soil-structure interface was assumed to be rough. Preliminary investigations indicated that the introduction of an interface strength reduction factor $\left(\mathrm{R}_{\mathrm{inter}}\right)$ did not necessarily lead to a better fit between the experimental and FE results, so $R_{\text {inter }}$ was not used in the results presented in the remainder of this paper.

The slab-wall corner was assumed to be fixed as the corresponding joints in the centrifuge model were all either fully welded or made from continuous sheets of metal. This has led to an over-estimation of the bending moments that would be transmitted across the joint, but using a fixed joint did not provide a significantly better match than using a pinned joint.

The permeability of the clay was calibrated using experimental data and the permeability of the drainage layer was assumed to be 10 times that of the clay. This factor of 10 assumption accounts 
TABLE 4. Properties of soils used in finite elements model

\begin{tabular}{|c|c|c|}
\hline Soil type & $\begin{array}{l}\text { Over-consolidated } \\
\text { kaolin clay (HSS) }\end{array}$ & $\begin{array}{c}\text { Hostun sand } \\
\text { (Mohr-Coulomb) }\end{array}$ \\
\hline Dry density $\left(\mathrm{kg} / \mathrm{m}^{3}\right)$ & - & 1600 \\
\hline Saturated density $\left(\mathrm{kg} / \mathrm{m}^{3}\right)$ & 1750 & 2000 \\
\hline Initial voids ratio $\left(\mathrm{e}_{\mathrm{init}},-\right)$ & 1.00 & 0.64 \\
\hline Permeability $(\mathrm{k}, \mathrm{m} / \mathrm{s})$ & $5 \times 10^{-10}$ & $1 \times 10^{-4}$ \\
\hline Poisson ratio $(v,-)$ & 0.12 & 0.20 \\
\hline Confined modulus, $(\mathrm{E}, \mathrm{kPa})$ & - & 47500 \\
\hline Peak shear modulus $\left(\mathrm{G}_{0}, \mathrm{kPa}\right)$ & 45000 & - \\
\hline Reference strain for stiffness degradation $\left(\gamma_{\mathrm{ref}},-\right)$ & $2.5 \times 10^{-4}$ & - \\
\hline Unload-reload modulus $\left(\mathrm{E}_{\mathrm{ur}}, \mathrm{kPa}\right)$ & 16800 & - \\
\hline Reference secant modulus $\left(\mathrm{E}_{50}, \mathrm{kPa}\right)$ & 5600 & - \\
\hline Oedometric modulus $\left(\mathrm{E}_{\text {oed }}, \mathrm{kPa}\right)$ & 4800 & - \\
\hline Reference stress $\left(\mathrm{p}_{\text {ref }}, \mathrm{kPa}\right)$ & 250 & - \\
\hline Exponent of stress dependence $(\mathrm{m},-)$ & 0.65 & - \\
\hline Angle of friction $\left(\phi,^{\circ}\right)$ & 23 & 33 \\
\hline Angle of dilation $\left(\psi,{ }^{\circ}\right)$ & 0 & 20 \\
\hline Apparent cohesion ( $\mathrm{c}^{\prime}$ ref, $\left.\mathrm{kPa}\right)$ & 0 & 1 \\
\hline Failure ratio $\left(\mathrm{R}_{f},-\right)$ & 0.8 & - \\
\hline
\end{tabular}

for the ingress of clay particles into the sand drainage layer and a comparison of slab bending moments (Fig. 11) seems to show that this assumption led to good predictions of under-slab excess pore pressure.

Each FE simulation was initialised with greenfield conditions to establish the geo-static stresses. This is equivalent to swinging up the centrifuge and increasing the gravity from $1 \mathrm{~g}$ to $100 \mathrm{~g}$. The soil in the space to be occupied by the basement was then replaced by the basement structure. Line loads were applied to the inside of the wall and slab elements to represent the hydrostatic pressure exerted by the heavy fluid in the centrifuge tests. The model was then allowed to reach equilibrium; this equilibrium would be taken as the datum of subsequent displacement readings.

The removal of the heavy fluid in the centrifuge test, which simulated the excavation process, was modelled in FE by reducing the line loads on the inside of the basement structure elements 
correspondingly. The application of superstructure load in the centrifuge test was modelled in FE by applying corresponding point loads on the top of the walls. Each construction stage was performed using the "Consolidation" calculation type with finite construction durations, leading to fully coupled simulations of effective stresses and pore pressures; for the stages where the model was left to consolidate to equilibrium, an excess pore pressure limit of $1 \mathrm{kPa}$ was used. The duration of each construction phase in the FE model matched the corresponding centrifuge test stage at prototype scale, following the sequence listed on Table 3 . This enables a direct comparison between the centrifuge results and the results from the numerical analysis.

\section{COMPARISON BETWEEN CENTRIFUGE AND NUMERICAL RESULTS}

\section{Vertical Heave}

The vertical displacement of the base slab is the most commonly measured quantity in research about the phenomenon of basement heave. Vertical displacements affect the serviceability of the slab and the functionality of the basement space directly. Fig. 8 plots the profiles of displacement of the base slabs at four different construction stages after excavation, compared to their positions immediately before excavation. The timestamps on Fig. 8 are given relative to the start of excavation.

When the hydrostatic loads in the basement cavity were removed to simulate excavation, an undrained response was invoked in the clay layer, resulting in immediate heave. The underside of the slab subsequently felt an increase in swell pressure that resulted in further upward displacement of the slab. The rest of this paper will focus on the base slab's behaviour from the start of excavation (Stage 3 on Table 3) to the equilibrium with light superstructure load (Stage 6). Chan et al. (2019b) provides further discussion on the effect of heavy superstructure loads (Stage 7).

Comparing the experimental measurements with the FE results, the stiff basement prototype showed better agreement in the "excavated" and "hiatus" stages, whereas the flexible basement prototype showed better agreement in the "light superstructure construction" and "light superstructure long-term" stages. A comparison between the "hiatus" plot and the "light superstructure construction" plot shows that the FE model was unable to capture the immediate total settlement 
of the stiff slab and the immediate settlement of the centre of the flexible slab in response to the application of superstructure load.

The error bound of experimental measurements of displacement in response to superstructure loading was less than $10 \mathrm{~mm}$ (at prototype scale), so this discrepancy was a weakness of the FE model. It was conjectured that the discrepancy may have arisen from the simplification of the 3D experimental set-up into a 2D FE model, or to a lesser degree from the assumption of a rough interface between the basement wall and the sand in the FE model. Additional attempts were made to simulate the stiff basement prototype, firstly in $3 \mathrm{D}$, and secondly in $2 \mathrm{D}$ with a smooth wallsoil interface. However, all these models of the stiff basement under-estimated the instantaneous settlement caused by the application of superstructure loads between the "hiatus" and completion of the "light superstructure construction" stages compared to the experimental observations.

It was therefore concluded that the discrepancy was caused by the constitutive model overestimating the undrained stiffness of the clay upon stress reversal. In hardening soil models such as HSS, stiffness and strength parameters are defined in terms of effective stresses. Where undrained behaviour is required, the stiffness of water is superimposed upon the effective stiffness of the soil to obtain the undrained stiffness of the saturated soil. Previous research has shown that this approach does not necessarily lead to accurate estimates of undrained stiffness (see e.g. Surarak et al. 2012).

Nevertheless, the discrepancy between experimental measurements and FE were limited to the excavation and construction stages. The FE model produced accurate predictions of the change in displacement between the short-term and long-term conditions after construction for both prototypes. As any unevenness of base slabs are usually corrected in subsequent construction stages, this discrepancy between experimental and FE results is unlikely to lead to problems when used for real construction projects.

\section{Excess Pore Pressure}

The time dependency of heave phenomena is driven by the generation and dissipation of excess pore pressures. Fig. 9 plots the FE results of excess pore pressures immediately after excavation of the flexible basement. A bulb of relative suction was formed underneath the base slab in response to 

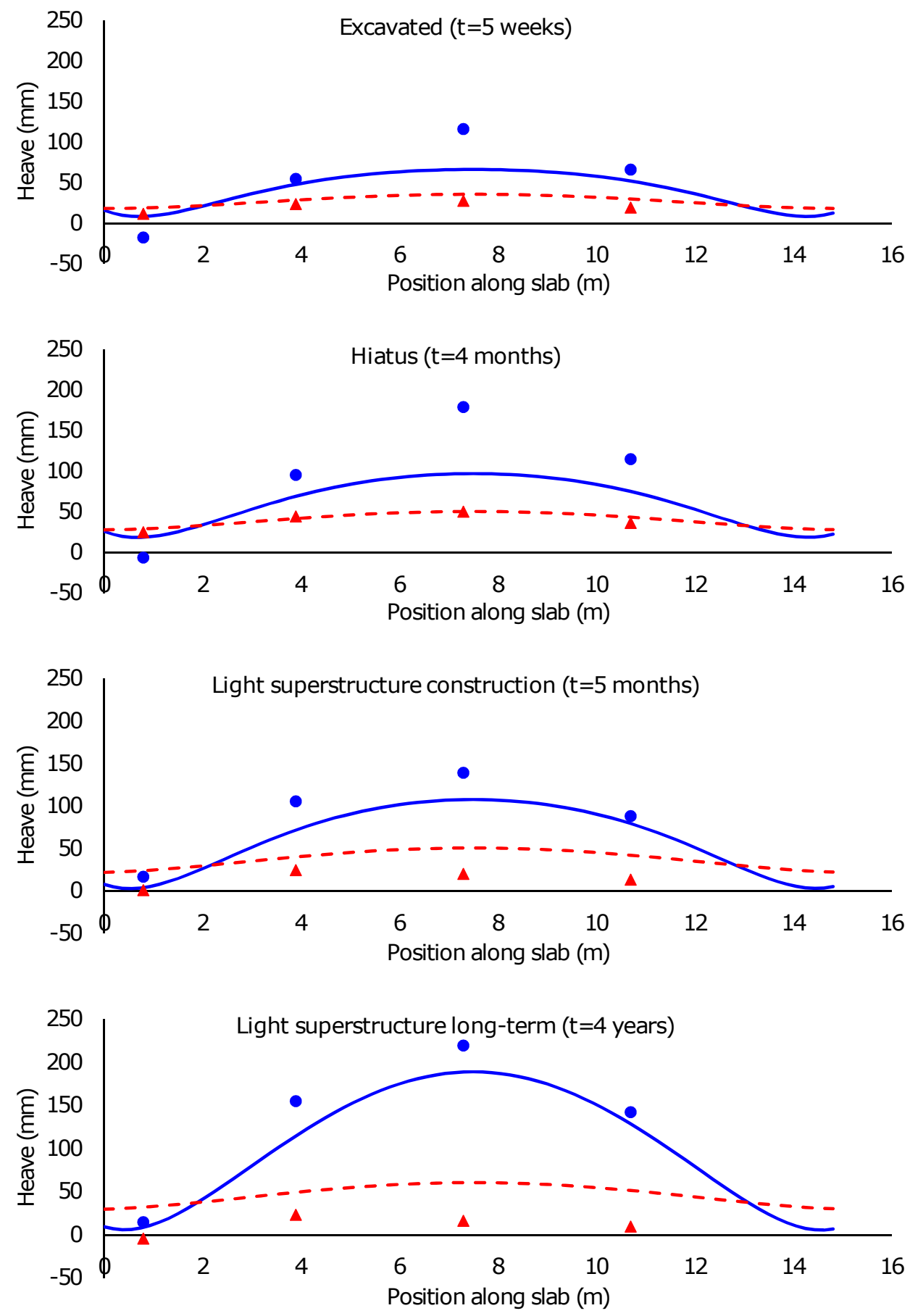

— Flexi (FE) - Flexi (Expt) - - - Stiff (FE) $\quad \Delta \quad$ Stiff (Expt)

Fig. 8. Profiles of heave displacement along centreline of basement slab 

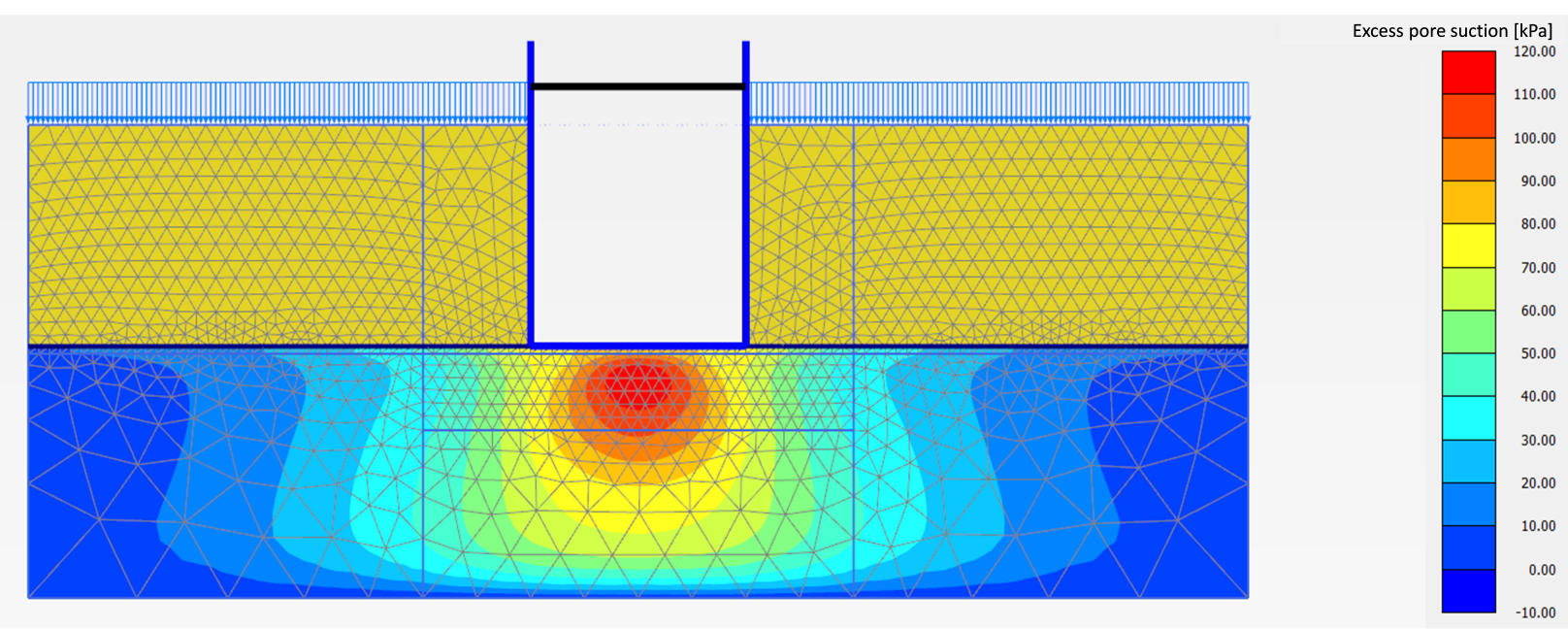

Fig. 9. Plot of excess pore suction in FE model immediately after excavation of flexible basement

excavation. The gradual dissipation of these excess pore pressures after excavation led to increased displacements and slab-soil contact pressures.

There is a good agreement between the experimental measurements and numerical predictions of pore pressures. Fig. 10 shows the excess pore pressures measured at $5 \mathrm{~m}$ below formation level for both centrifuge tests and compares them to FE results; the numbers in brackets correspond to construction stages given in Table 3. Both the centrifuge model and the FE simulation recorded about $95 \mathrm{kPa}$ of negative excess pore pressure in response to the excavation of the flexible basement, and about $80 \mathrm{kPa}$ for the stiff basement (Stage 3), followed by gradual dissipation towards equilibrium (Stages 4-6).

\section{Bending Moment in Base Slab}

In the construction of reinforced concrete basement structures, bending moments in the base slab dictate the amount of steel reinforcement that needs to be provided. The bending curvatures measured by the strain gauges in the centrifuge test are scaled up using the bending stiffness of the slab (EI/b) to give measurements of bending moment. These are plotted alongside FE results for 


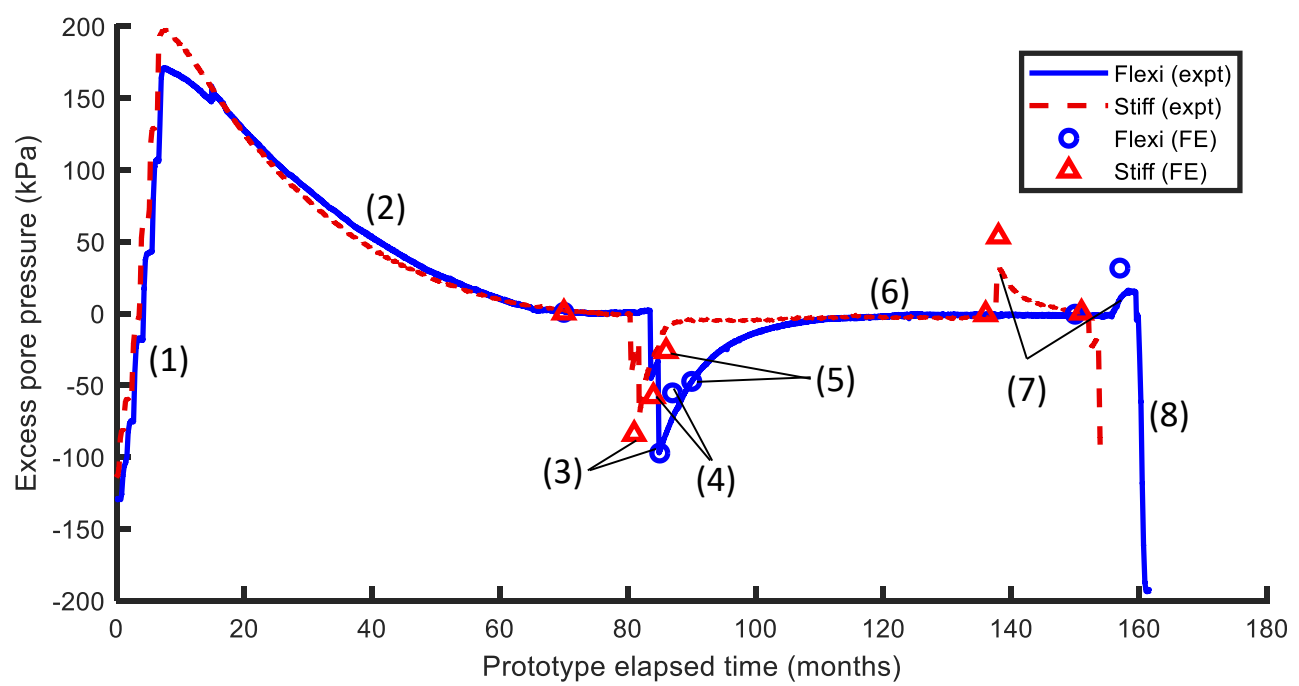

Fig. 10. Plot of variation of excess pore pressure with time at $5 \mathrm{~m}$ below centre of slab (see Table 3 for construction stage descriptions)

bending moments in Fig. 11; timestamps are given relative to the start of excavation as with Fig. 8. In the FE models, "fully fixed" conditions were used at slab-wall joints, as explained earlier.

For the flexible slab, there was a good agreement between the experimental and FE results for the middle part of the slab at all construction stages. The FE model was able to reproduce the dip in the middle of the bending moment profile which was caused by pore water suction under the slab.

For the stiff slab, the FE model was able to produce the overall trend and magnitude of the bending moments but tended to underestimate the bending moments in the slab, particularly near the edges of the slab. The FE models for both prototypes computed large negative bending moments near the edges of the slabs, which were not observed in the centrifuge tests. This occurred because the slab-wall connection was assumed to be rigid in the FE model, leading to an over-estimation of joint stiffness. However, a parametric study has shown that assuming a pin joint at the slab-wall connection would over-estimate the hogging moments in the slab and exacerbate the misfit of vertical displacement predictions (Figure 12), so it was concluded that the fixed joint assumption provided a better fit.

Another source of error may be the simplification of the analysis into a 2D plane strain model: the measured bending curvatures were scaled up to give values of bending moment without accounting 

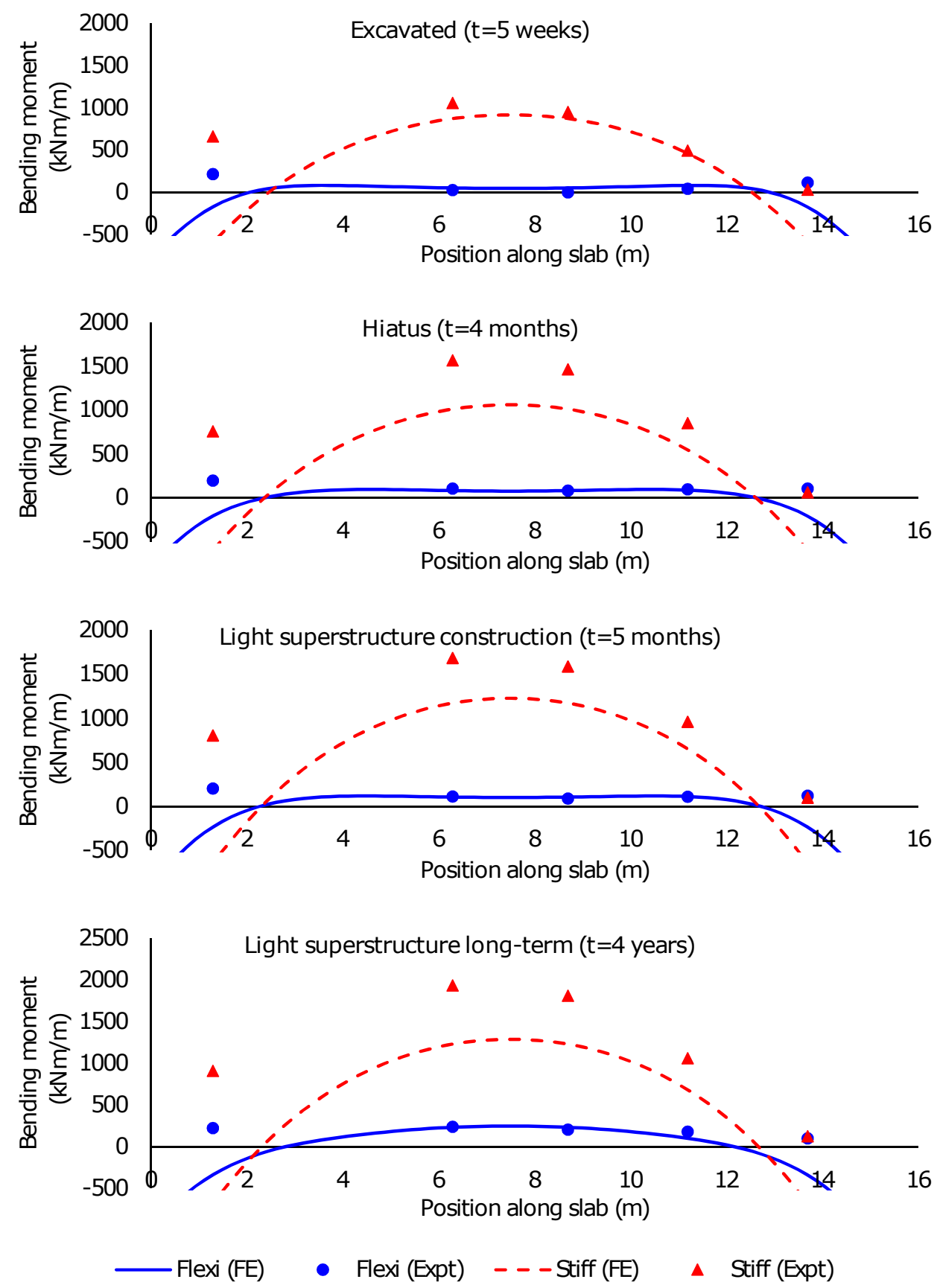

Fig. 11. Profiles of bending moment along centreline of basement slab

for the influence of out-of-plane bending stresses, and the FE model was performed in 2D. This affects the stiff base slab more because it attracts higher out-of-plane bending moments than the flexible slab. 

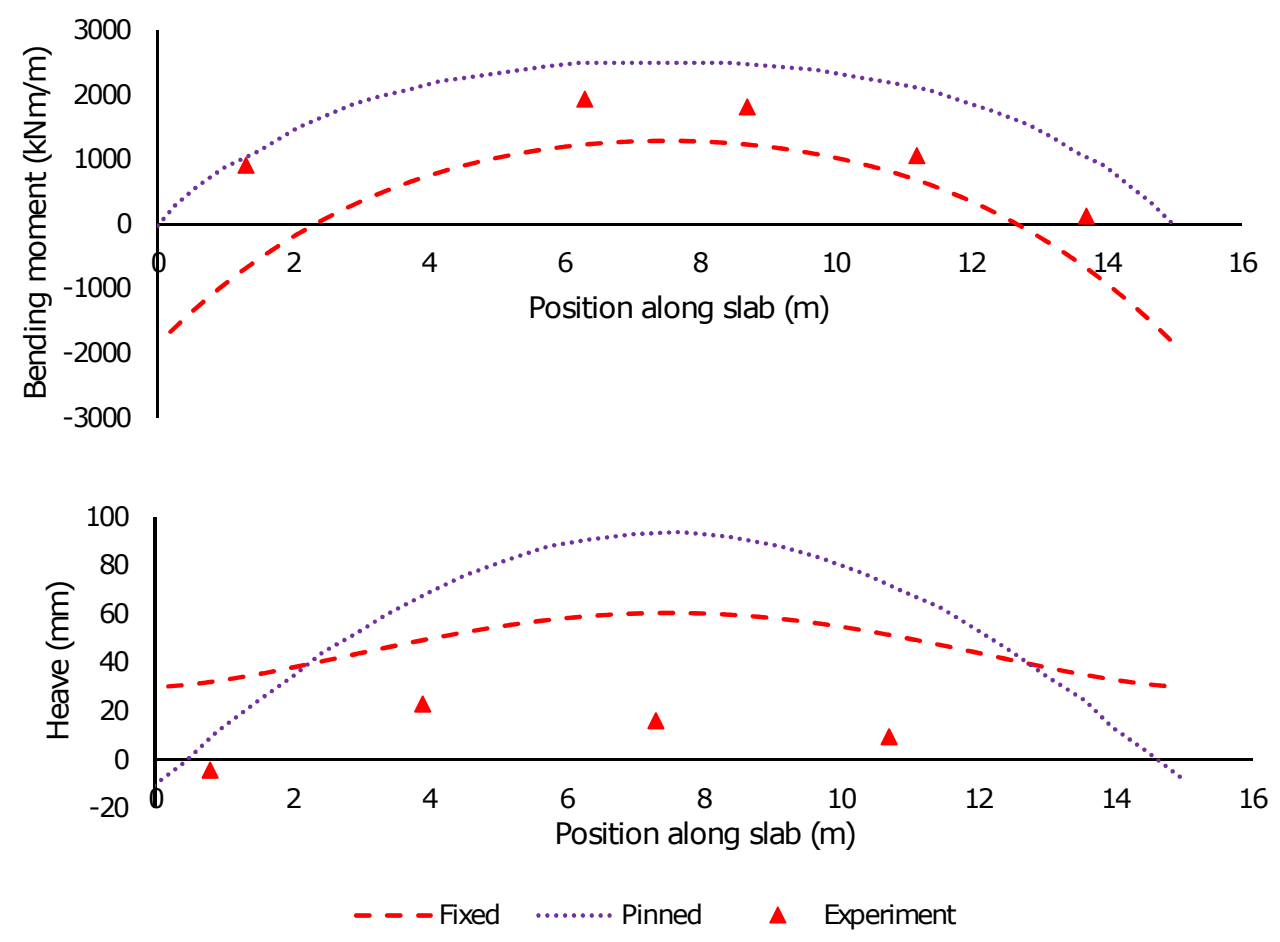

Fig. 12. Comparison of fixed joint and pinned joint FE results at long-term equilibrium along centreline of stiff slab

\section{Slab-Soil Contact Pressure}

The slab-soil contact pressure at formation level is often used as a design parameter in the design of basements where significant long-term heave is expected.

The most innovative feature of the centrifuge tests presented in this paper was that a tactile sensing mat was used to measure the distribution of soil-structure contact pressures. Chan et al. (2019a) discussed the calibration of tactile sensing mat readings. The calibrated results are presented in Fig. 13 and compared to FE predictions.

The plot of pre-excavation contact pressure shows that the FE model predicted a uniform pressure underneath the slab except at the edges. The centrifuge model recorded much more variation in the pressure profile. This discrepancy may be due to the artefacts introduced by the centrifuge spin-up process, which were not modelled in FE, particularly for the flexible slab case.

The contact pressures dropped sharply as each basement was excavated, with the edges of the slab retaining more pressure than the middle of the slab. For the flexible basement, there was nearly 
complete loss of pressure in the middle half of the basement breadth. For the stiff basement, the pressure at the middle of the slab dropped from about $250 \mathrm{kPa}$ to about $100 \mathrm{kPa}$.

The contact pressures increased as the excess negative pore pressure in the clay underneath each basement dissipated. The consequent reduction in effective stress in this region caused the clay to swell and generated the upwards swell pressure on the underside of the slab. The increase in pressure was more prominent near the sides of the basement than the middle. In both cases, the edges of the basement retained a vertical stress of about $250 \mathrm{kPa}$ in long-term equilibrium, similar to the pre-excavation vertical stress, and a lower contact pressure was recorded towards the middle of the basement.

For both the short-term condition after excavation and the long-term equilibrium condition, there was agreement between the experimental measurements and the FE predictions of slab-soil contact pressure.

\section{Props}

Another aspect of comparison between the centrifuge models and the FE models is the load in the props. Since the props were located at the top of the basement, agreement between the FE-simulated prop forces and the experimentally measured values should give confidence that the FE model was able to reproduce the overall deformation mechanism of the basement.

The results in Fig. 14 show that, from the excavation stage onwards, the FE model successfully reproduced the trend and approximate magnitude of the prop force. (The numbers in the brackets show the construction stages identified in Table 3.) In each case, the prop force increased slightly in response to the imposition of the light superstructure load and did not change significantly during the consolidation phase. The imposition of the heavy superstructure load again raised the prop force. For the stiff basement prototype where the centrifuge test kept running for a substantial period of time after the imposition of the heavy superstructure load, the centrifuge test and FE model were also in good agreement about the increase in prop load due to reconsolidation.

There are two main aspects of discrepancy between the centrifuge results and FE results. First, the FE model did not reproduce the significant compression registered by the flexible basement 

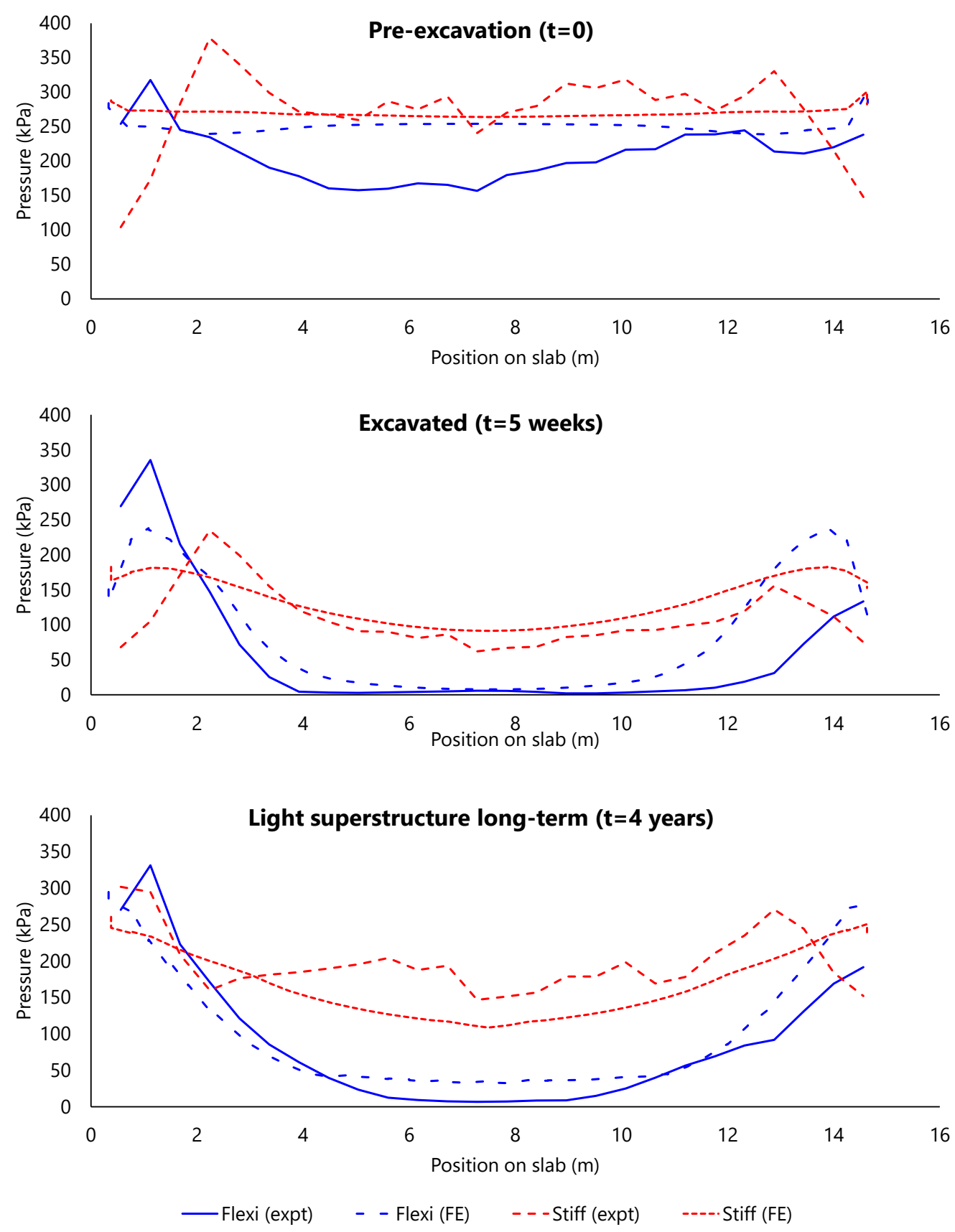

Fig. 13. Plots of slab-soil contact pressure along centreline of slab

props in response to spin-up. This arose from the fact that the FE model did not seek to replicate the process of centrifuge spin-up. Second, there is a general offset between the exact numerical values of the prop forces from the two methods of investigation, possibly because the end walls of the experimental basement shared some lateral loads while the FE model was purely two-dimensional. 


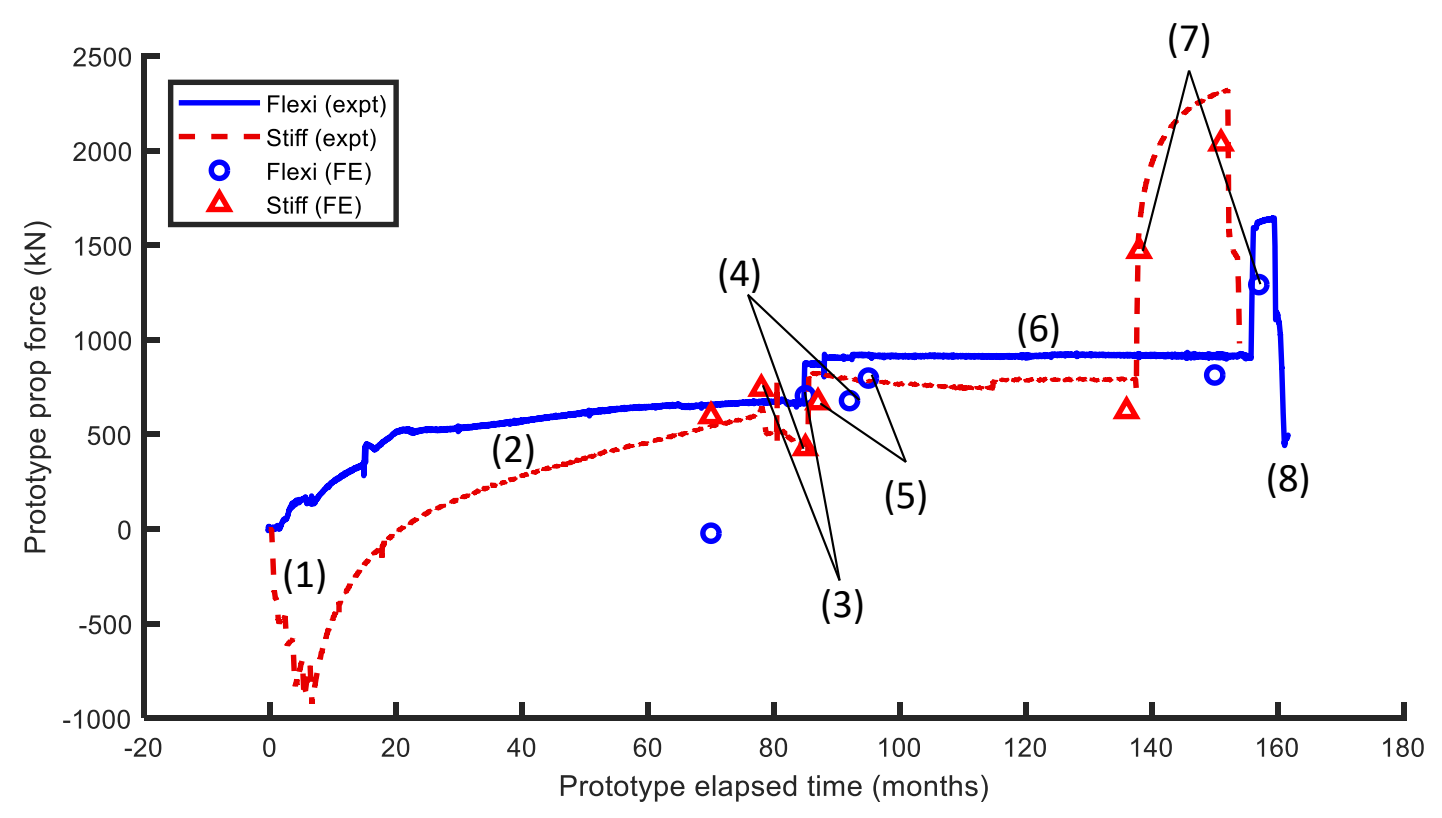

Fig. 14. Plot of variation of prop force with time (see Table 3 for construction stage descriptions)

\section{REFINEMENT OF SEMI-ANALYTICAL PREDICTIONS}

The comparison between experimental and FE results have shown largely a good agreement between the measured and simulated slab-soil contact pressures. Furthermore, the FE models provided good estimates of equilibrium vertical displacement for the flexible basement and a conservative estimate of vertical displacement for the stiff basement. These results can be used to refine the semi-analytical methods of heave prediction that are currently used in industry.

In the relaxation ratio method, the under-slab pressure is often assumed to be uniform. A range of values for this uniform vertical stress are imposed onto the clay stratum and the base slab to generate the soil curve and the structure curve respectively, and the intersection between the two curves gives the predicted heave displacement and swell pressure, as shown in Fig. 1.

However, the results presented in this paper have shown that the under-slab pressure can be more accurately approximated as a parabolic distribution. The slab-wall connection restrains the the edges of a base slab from significant vertical displacement during long-term heave, hence it is intuitively correct that the equilibrium vertical effective stress at the edges of the slab should be approximately equal to the pre-existing effective overburden at formation level $\left(\sigma_{v 0}^{\prime}\right)$. The profile 


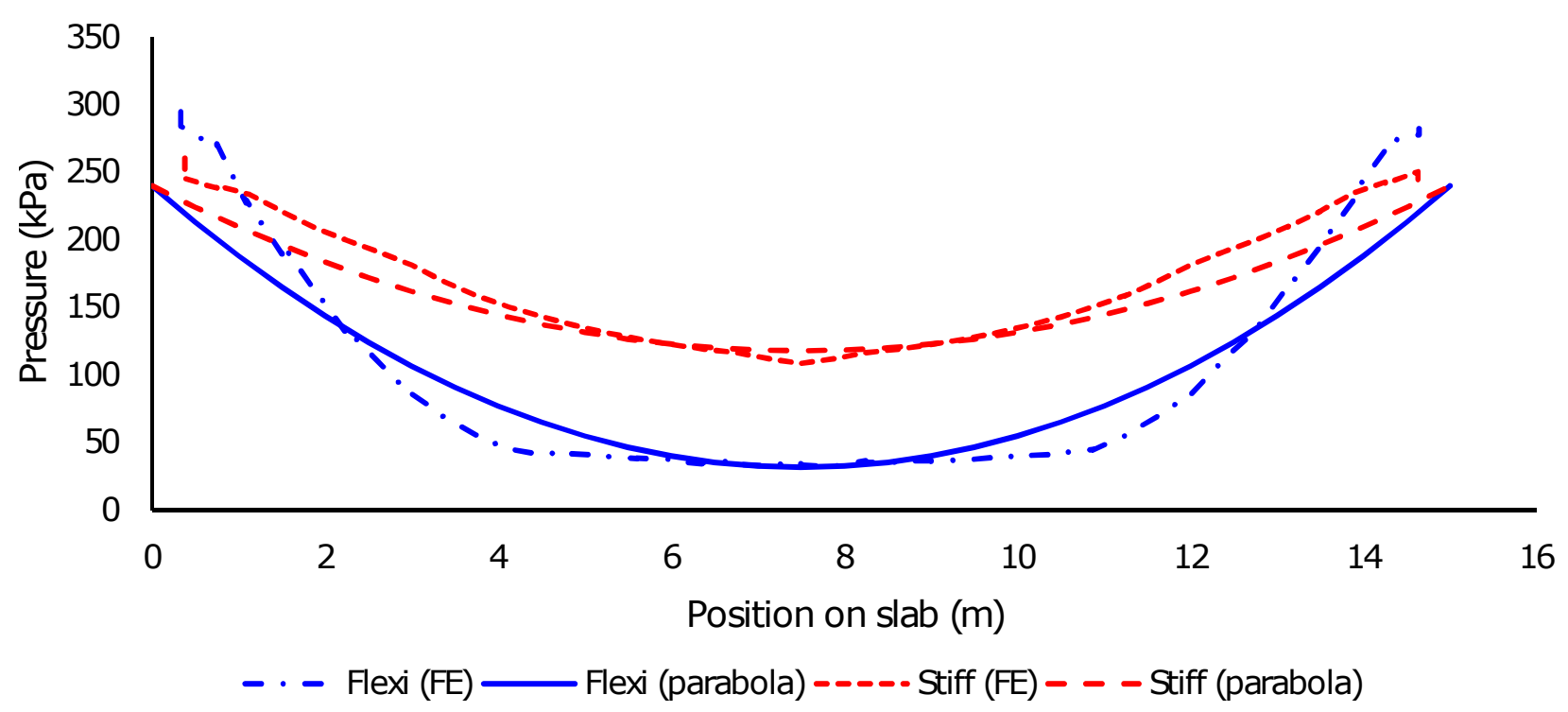

Fig. 15. Parabolic fit of slab-soil contact pressure

of under-slab vertical stress can then be approximated as a quadratic curve that drops from $\sigma_{v 0}^{\prime}$ at the edges to a lower value $\sigma_{v c}^{\prime}$ at mid-span (Fig. 15).

The profile of heave can similarly be approximated as a parabola that increases from zero at the slab-wall connections to a maximum value $\delta_{c}$ at mid-span. The values of $\sigma_{v c}^{\prime}$ and $\delta_{c}$ can then be used as the variables of a relaxation ratio method analysis.

\section{Relaxation Ratio Method}

To generate the soil curve, calculate $\delta_{c}$ due to various values of $\sigma_{v c}^{\prime}$ ranging between zero and $\sigma_{v 0}^{\prime}:$

1. Pick a value of $\sigma_{v c}^{\prime}$, and impose the corresponding quadratic profile of the change in equilibrium vertical stress $\Delta \sigma_{v}^{\prime}=\sigma_{v 0}^{\prime}-\sigma_{v}^{\prime}$ to the slab-soil interface.

2. Use Steinbrenner's algorithm (see Bowles 1997) to obtain the distribution of changes in vertical stress in the clay stratum. This is the most computationally intensive part of the analysis, but Steinbrenner's algorithm assumes linear elasticity so it only needs to be run once. The resulting stress distribution can be scaled linearly for other values of $\sigma_{v c}^{\prime}$.

3. Use the oedometric method (Padfield and Sharrock 1983; O'Brien and Sharp 2001) to calculate the heave displacement at the centre of the slab $\left(\delta_{c}\right)$. This step introduces the 


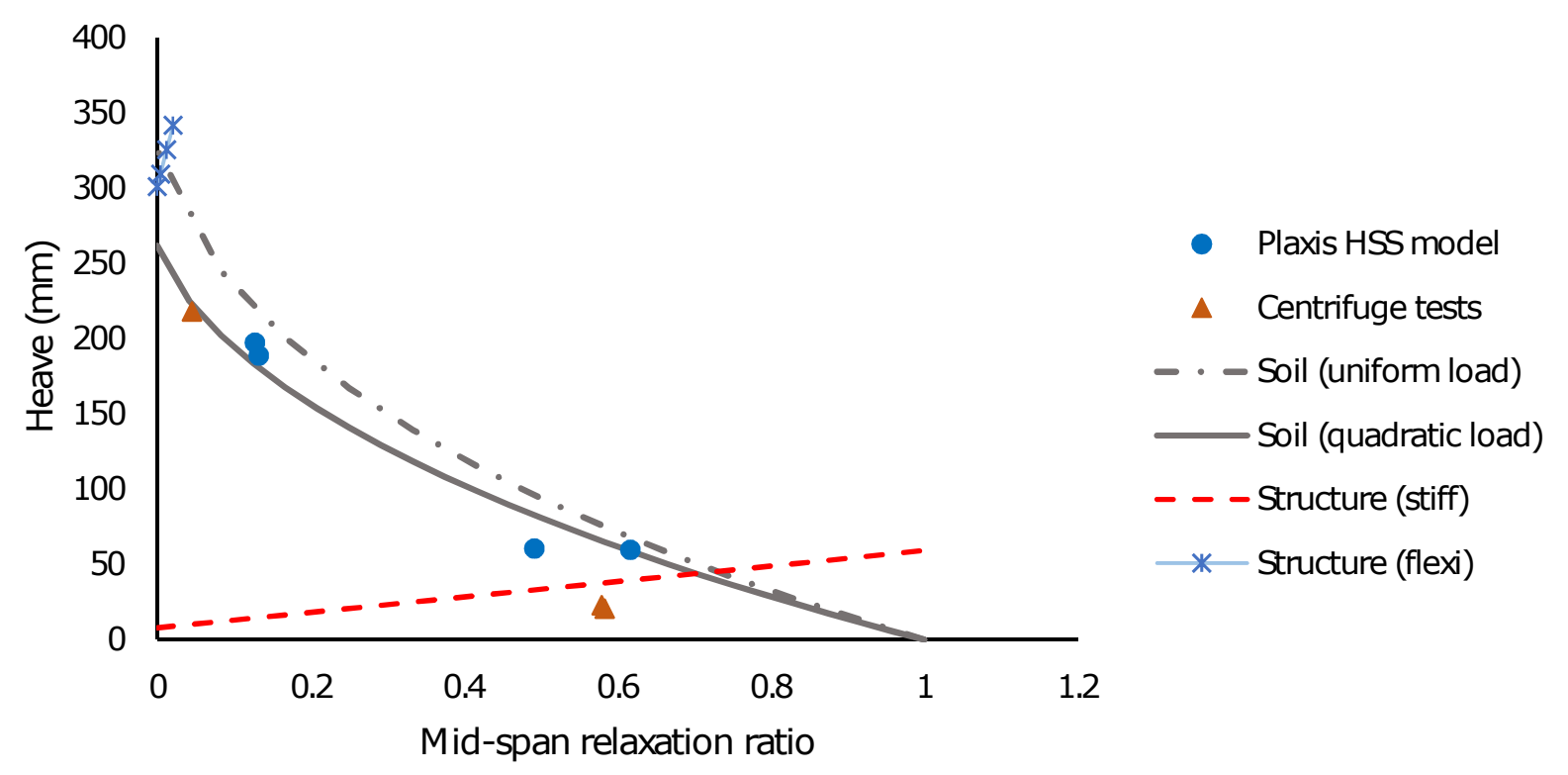

Fig. 16. Relaxation ratio plot for the prototypes investigated in this research

non-linearity of soil stiffness.

4. Repeat for other values of $\sigma_{v c}^{\prime}$ and plot a curve of $\delta_{c}$ versus the mid-span relaxation ratio $\left(\sigma_{v c}^{\prime} / \sigma_{v 0}^{\prime}\right)$.

To generate a structure curve, impose the same quadratic load profiles onto the under-side of the slab and calculate the resulting heave displacement of the centre of the slab $\left(\delta_{c}\right)$. For linear-elastic structural elements, this will yield a structure curve that increases linearly with mid-span relaxation ratio $\left(\sigma_{v c}^{\prime} / \sigma_{v 0}^{\prime}\right)$. The intercept of the structure curve is generally not zero because $\sigma_{v c}^{\prime} / \sigma_{v 0}^{\prime}=0$ means that the vertical stress at mid-span is zero but the vertical stress at the edge of the slab is still close to $\sigma_{v 0}^{\prime}$.

Fig. 16 plots the soil curves and structure curves for the prototypes presented in this paper alongside values of mid-span heave displacement and contact pressure for the centrifuge tests and FE models. A comparison between the two soil curves shows that switching from a uniform load profile assumption to a quadratic load profile assumption has led to a better fit with the experimental data and FE simulation results while remaining suitably conservative.

With a quadratic load assumption, the structure curve for the stiff basement prototype intersected 
with the soil curve at a point that predicted slightly higher heave displacement and swell pressures than the experimental results, which is again a conservative prediction.

For the flexible structure, the structure curve begins at an intercept of $\delta_{c}=300 \mathrm{~mm}$, higher than the intercept of the soil curve. That means a quadratic load distribution is conservative and the actual contact pressures would be lower than a quadratic distribution would predict. This was indeed observed in the experiment and FE simulation of the flexible basement prototype. In this case, the relevant prediction of swell pressure should be taken as a quadratic distribution with complete relaxation of load at mid-span and the pre-existing overburden $(240 \mathrm{kPa})$ at the edges; the corresponding prediction of heave displacement would be $\delta_{c}=261 \mathrm{~mm}$.

Moving from a uniform pressure distribution to a quadratic pressure distribution also solves the problem that clay has zero unconfined stiffness so the values of predicted heave would be unreasonably high at very low values of relaxation ratio. With a quadratic pressure distribution, most of the soil still retains a substantial vertical effective stress even at $\sigma_{v c}^{\prime}=0$, leading to better numerical stability.

\section{Relative Stiffness Method}

Alternatively, the data can be non-dimensionalised by considering the relative stiffness between the slab and the clay stratum as the independent variables, and the equilibrium effective heave pressure at mid-span as the dependent variable.

The relative stiffness between the slab and the soil can be expressed as:

$$
R_{s}=\frac{E_{s} t^{3}}{\sigma_{v 0}^{\prime} L^{3}}
$$

Where $E_{s}$ is the Young's modulus of the basement slab material, $\mathrm{t}$ is the thickness of the slab, $\mathrm{L}$ is the width of the basement, and $\sigma_{v 0}^{\prime}$ is the in-situ vertical stress at formation level before excavation. $\sigma_{v 0}^{\prime}$ is chosen to represent the stiffness of the clay because the stiffness of clay depends strongly on confining stress, so the in-situ vertical stress provides a stable measure of stiffness that does not depend on parameter fitting. $R_{S}$ is plotted in logarithmic scale because the stiffness of 


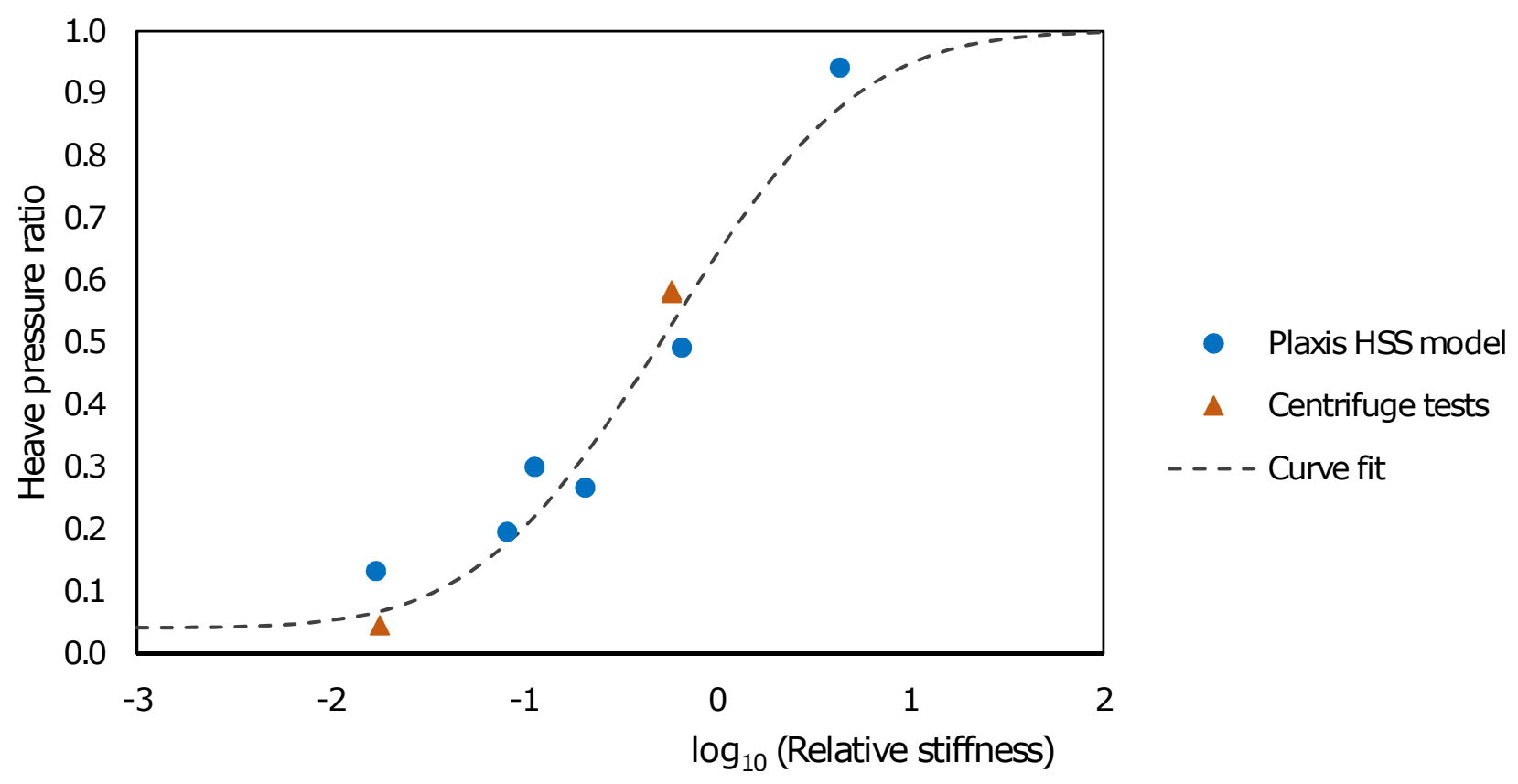

Fig. 17. Plot of non-dimensionalised heave pressure versus relative stiffness for the prototypes investigated in this research

base slabs can vary over many orders of magnitude.

The heave pressure ratio is defined as the proportion of excavated overburden that manifests itself as effective swell pressure at mid-span in long-term equilibrium:

$$
R_{p}=\frac{\sigma_{v c}^{\prime}}{\sigma_{v 0}^{\prime}}
$$

Data from the centrifuge tests and the results from FE models were plotted in these nondimensionalised units in Fig. 17. In addition to the data presented in Fig. 1, four additional FE models were added to the graph, representing the heave behavior of basements of the same depth but different widths, founded on the same soil strata and subject to the same construction sequence.

Intuitively, this heave pressure ratio should approach unity for very large stiffness values, and the lower bound of heave pressure should be conservatively taken as the self-weight of the slab per unit area. An S-curve is fitted to the data using the Gauss error function:

$$
R_{p}=\frac{1}{2}\left(1+R_{B}\right)+\frac{1}{2}\left(1-R_{B}\right) \operatorname{erf}\left(\frac{\log _{10}\left(R_{s}\right)-R_{\mu}}{R_{\sigma}}\right)
$$


This gives an S-curve which starts at the lower bound value of $R_{p}=R_{B}$, rises to its halfway point at $\log _{10}\left(R_{s}\right)=R_{\mu}$ with a Gaussian standard deviation of $R_{\sigma}$, and tends towards $R_{p}=1$ for large values of Rs. For the data presented in Fig. 17, the best-fit parameters are given as:

- $R_{B}=0.042$ (ratio of self-weight of flexible slab prototype to in-situ vertical stress)

- $R_{\mu}=-0.25$

- $R_{\sigma}=1.1$

This best-fit curve may be used as a rough guide for the relationship between base slab stiffness and expected swell pressure at mid-span. The quadratic load distribution may then be used to obtain the profile of expected swell pressure, and then the stiffness of the slab be used to obtain the profile of expected heave displacement.

This relative stiffness design curve was generated using a small set of experimental and computational data involving one basement depth and one type of clay only, so it might not be representative of all basements subject to long-term heave. Nevertheless, it is hoped that this non-dimensionalised curve would form the framework of an improved design guide for basement slabs subject to longterm heave, and the parameters of the curve can be refined when more physical and computational results are added to the dataset. It will be of significant benefit to the industry if more site monitoring data of under-slab swell pressures and vertical displacements of base slabs are made available. As more physical and computational data are obtained, the following aspects of the best-fit curve may need to be refined:

- The shape of the S-curve was assumed to take the shape of the Gaussian error curve. Other S-curve shapes (e.g. logistic distribution) may produce a better fit as more data points become available.

- The thickness of the clay stratum was not used in the definition of relative stiffness, as using $L^{3}$ in the denominator of $R_{s}$ gave the best non-dimensionalisation of the available data points. The data presented in Fig. 17 only represented basement width $(L)$ to stratum thickness $(H)$ ratios of $0.5<L / H<2$. It is expected that, if $H<<L, H$ will become a 
significant factor controlling the swell pressure.

- The mineralogy of the clay did not play a role in the definitions of the S-curve parameters. As data from different types of over-consolidated clay are compared against each other, the parameters will need to be revised to account for differences in mineralogy, likely by including the swelling index of clay $C_{s}$ into the nominator of $R_{s}$.

\section{CONCLUSIONS}

The long-term heave behaviour of two rectangular basement prototypes underlain by overconsolidated clay were investigated both by centrifuge modelling and by FE modelling using Plaxis 2D. The clay was modelled using the HSS constitutive model. The prototypes had the same plan area and depth, but differed in terms of slab and wall stiffness. The profiles of vertical displacements of the base slab, bending moments in the slab, slab-soil contact pressures, and prop forces were measured and compared to the numerical solutions.

For the flexible slabs, there is a good agreement between the experimental and FE data for vertical displacement, bending moments, and slab-soil contact pressure. In long-term equilibrium, the profiles of displacement and pressure both appear to follow a parabolic trend which transitions from the pre-excavation values at the edges of the slab (zero displacement, same vertical stress as the pre-existing overburden) to an apex value at mid-span (maximum displacement, minimum vertical stress).

For the stiff slabs, there is good agreement between the experimental and FE data in terms of slab-soil contact pressure, but the FE model appears to over-estimate the equilibrium displacement. HSS appeared to over-estimate the undrained stiffness of the clay, leading to over-predictions of overall heave in cases where the construction of the sub-structure is expected to cause significant undrained settlement.

The findings of this study can be used to improve the semi-analytical methods used in industry to design basement slabs in geological units where significant long-term heave is expected. By assuming a parabolic distribution rather than a uniform distribution of effective heave pressure, the relaxation ratio method can give more accurate predictions of heave while remaining suitably 
conservative. An empirical chart of contact pressure at mid-span versus relative stiffness may also be plotted to give a first estimate of the profile of long-term heave pressure.

\section{DATA AVAILABILITY STATEMENT}

All data, models, or code generated or used during the study are available in the University of Cambridge Repository at https://doi.org/10.17863/CAM.66654 in accordance with funder data retention policies.

\section{ACKNOWLEDGEMENTS}

The authors would like to thank technical staff Mr. J.A. Chandler, Mr. K.D. Pether, Mr. M. Smith, and Mr. C.J. McGinnie for facilitating the experiments; and to Mr. A. Locke, Mr. V.C. Walford, Mr. K. Miller, Mr. S.A. Solera, Prof. A.S. O’Brien, and Dr. W. Kesse for their advice on current design and construction practices. The authors would also like to acknowledge the EPSRC Centre for Doctoral Training in Future Infrastructure and Built Environment at the University of Cambridge (EPSRC grant reference number EP/L016095/1) and Mott MacDonald Geotechnics for supporting this research project.

\section{REFERENCES}

Bowles, J. E. (1997). Foundation Analysis and Design. McGraw-Hill.

Chan, D. Y. K. and Madabhushi, S. P. G. (2017). "Designing urban deep basements in South East England for future ground movement: Progress and opportunities for experimental simulation of long-term heave." International Symposia for Next Generation Infrastructure, London (September).

Chan, D. Y. K. and Madabhushi, S. P. G. (2020). "Centrifuge and numerical modelling of the influence of structural stiffness on basement heave in over-consolidated clay." 10th International Symposium on Geotechnical Aspects of Underground Construction in Soft Ground.

Chan, D. Y. K., Madabhushi, S. P. G., Haigh, S. K., and Deng, C. (2019a). Calibration of tactile pressure sensing mats for static geotechnical centrifuge applications. 
Number CUED/D-SOILS/TR.349 in CUED Technical Reports. Cambridge University, $<$ http://doi.org/10.17863/CAM.47793>.

Chan, D. Y. K., Madabhushi, S. P. G., Hsu, Y. S., O’Brien, A. S., Solera, S. A., and Williamson, M. (2019b). "Experimental study of structural movements and swelling pressures on deep basements caused by long-term heave in over-consolidated clay." European Conference on Soil Mechanics and Geotechnical Engineering.

Chan, D. Y. K., Madabhushi, S. P. G., Nicholson, D. P., Chapman, T. J. P., and Solera, S. A. (2018). “Twenty-one years of heave monitoring in London Clay at Horseferry Road basement.” Ground Engineering, 51(11), 28-33.

Deng, C. and Haigh, S. K. (2018). "Soil movement mobilised with retaining wall rotation in loose sand." International Conference on Physical Modelling in Geotechnics, London, Taylor \& Francis (July).

Eadington, J. M. and O’Brien, A. S. (2011). “Stiffness parameters for a deep tunnel - Developing a robust parameter selection framework." European Conference on Soil Mechanics and Geotechnical Engineering, 531-536.

Ellis, E. A. and Springman, S. M. (2001). "Full-height piled bridge abutments constructed on soft clay." Géotechnique, 51(1), 3-14.

Heron, C. M. (2013). "The dynamic soil structure interaction of shallow foundations on dry sand beds." PhD thesis, University of Cambridge, Cambridge, UK (August).

Lam, S. S. Y., Haigh, S., Elshafie, M., and Bolton, M. (2012). “A new apparatus for modelling excavations.” International Journal of Physical Modelling in Geotechnics, 12, 24-38.

Madabhushi, S. P. G. (2014). Centrifuge Modelling for Civil Engineers. CRC Press (July).

Madabhushi, S. P. G., Houghton, N. E., and Haigh, S. K. (2006). "A new automatic sand pourer for model preparation at University of Cambridge." Physical Modelling in Geotechnics.

Mair, R. J., Phillips, R., Schofield, A. N., and Taylor, R. N. (1984). "Application of centrifuge modelling to the design of tunnels and excavations in soft clay." The Application of Centrfuge Modelling to Geotechnical Design, 357-380. 
May, J. (1975). "Heave on a deep basement in the London clay." Proceedings of the Conference on Settlement of Structures.

Nejjar, K., WItasse, R., Dias, D., Cuira, F., and Burlon, S. (2019). “Accounting for nonlinear behavior of ground for the prediction of settlements due to deep excavations." European Conference on Soil Mechanics and Geotechnical Engineering, Reykjavik (September).

O’Brien, A. S. and Sharp, P. (2001). "Settlement and heave of overconsolidated clays - A simplified non-linear method of calculation." Ground Engineering, 34(10), 28-32.

Obrzud, R. and Truty, A. (2011). “The hardening soil model - a practical guidebook.” Report No. 100701, Zace Services Ltd, Lausanne, Switzerland (March).

Padfield, C. J. and Sharrock, M. J. (1983). "Settlement of structures on clay soils." Report No. SP 27, CIRIA.

Plaxis (2017). "Plaxis Material Models Manual.

Pumphrey, L. (2001). "Heave at the Shell Centre.” M.S. thesis, Imperial College, London, UK.

Simpson, B. (2018). "Effective heave pressures beneath restrained basement slabs." Proceedings of the Institution of Civil Engineers - Geotechnical Engineering, 171(1), 28-36.

Simpson, B. and Vardanega, P. J. (2014). "Results of monitoring at the British Library excavation." Proceedings of the Institution of Civil Engineers: Geotechnical Engineering, 167(2), 99-116.

Surarak, C., Likitlersuang, S., Wanatowski, D., Balasubramaniam, A., Oh, E., and Guan, H. (2012). “Stiffness and strength parameters for hardening soil model of soft and stiff Bangkok clays." Soils and Foundations, 52(4), 682-697.

Vardanega, P. J., Lau, B. H., Lam, S. Y., Haigh, S. K., Madabhushi, S. P. G., and Bolton, M. D. (2012). "Laboratory measurement of strength mobilisation in kaolin: Link to stress history." Geotechnique Letters, 2(1), 9-15.

Viggiani, G. and Atkinson, J. H. (1995). "Stiffness of fine-grained soil at very small strains." Géotechnique, 45(2), 249-265.

Wongsaroj, J., Soga, K., and Mair, R. (2007). "Modelling of long-term ground response to tunnelling under St James's Park, London.” Geotechnique, 57(1), 75-90. 